\title{
Parental mental representations during late pregnancy and early parenthood following assisted reproductive technology
}

\author{
Francesca Agostini ${ }^{1}$, Fiorella Monti ${ }^{1}$, \\ Piergiuseppina Fagandini², Leonardo Llewellyn \\ Duncan De Pascalis², Giovanni Battista La \\ Sala ${ }^{2}$ and Isaac Blickstein ${ }^{3, *}$ \\ ${ }^{1}$ Department of Psychology, University of Bologna, \\ Bologna, Italy \\ 2 Department of Obstetrics and Gynecology, \\ Arcispedale Santa Maria Nuova, Reggio Emilia, Italy \\ ${ }^{3}$ Department of Obstetrics and Gynecology, Kaplan \\ Medical Center, 76100 Rehovot, Israel
}

\author{
Introduction
}

Mental representation is the generalized experience of interaction during early life with the primary caregiver, which constructs "working models" of interaction to be carried into adulthood [5, 45]. Mental representations are increasingly studied in relation to the mother's perception and interactive behavior with her newborn baby $[1,4,11$, $16,17,39,42,43,45,48,49,51]$, highlighting the importance of these psychological imprints from an intergenerational, attachment, and child development perspective.

During the perinatal period, when tremendous psychological and physiological changes occur [39, 44], the mental representations regarding maternity and being a child are strongly activated [1, 45], and include the mother's memories of early relationships, her fantasies, hopes, fears, family traditions, myths, and personal experiences [22, 45]. It has been noted that maternal representations of herself as a woman, wife, daughter, and career person are reorganized during pregnancy, as the woman makes space for her role as a mother [45]. It has been observed that representations regarding both the infant and herself as mother increase from the fourth to the seventh gestational month [1, 45, 46], whereas from about the eighth month onwards, representations become less active. In one theoretical frame, this decline in intensity of the positive representations is supposed to prevent disappointment [45], and from a neurobiological point of view, this may reflect the consolidation of the neural circuitry of attachment systems [25]. After birth, the mother rebuilds her representations, which become somewhat more coherent, flexible, and richer than those of pregnant women [1, 22].

Maternal representations can be translated into parenting styles [7]: they can predict postnatal perception of child temperament $[48,49,51]$ and feeding behavior independent of the actual skills and abilities of the child [40]. A more negative view of the child during pregnancy was associated with more problems in maternal interaction and/or number of depressive symptoms at six months [35]. More negative views of the child's father and own mother were associated with further motherinfant interaction problems [16].

In a psychosocial risk situation, a mother might have more difficulties in building up the representations of herself-as-mother and her infant and in adapting to the real situation of parenthood [28, 29, 41, 50]. Maternal risk 
factors such as poverty, low socioeconomic status, and domestic violence are indirectly related to infant-mother attachment by affecting maternal functioning and the way in which the mother thinks about the child [21]. Pajulo et al. [34] showed that the risk groups (depression, difficult social environment, low social support, and substance dependency) had more negative representations of the child, of self-as-woman and of self-asmother compared to non-risk groups. Subsequently, Pajulo et al. [36] showed that representations were more negative in content if the mother already had several small children or if the pregnancy was unplanned.

Patients undergoing assisted reproductive technology (ART) exhibit higher pregnancy-related distress and more emotional disturbances, including depressive and anxiety disorders [20, 27] compared to spontaneous conceptions [19, 30]. Italian studies showed that maternal representations in ART pregnancies are characterized by a defensive mechanism, manifesting as a representational void in regards to the child's future and self-as-parent [3]. Moreover, maternal representations frequently focused on actual concern about body and somatic complaints [3]. In contrast, Catalano et al. [8] found that maternal representations in ART pregnancies are characterized by a strong emotional involvement related to the process of pregnancy and to the relationship with the infant.

The present study investigates the maternal and paternal representations during late gestation and early life of the infant in spontaneous and ART pregnancies.

\section{Patients and methods}

This study is part of a larger project which measured depression, anxiety, and parental mental representations during the transition to parenthood in spontaneous and ART conceptions carried out in a single center. The first two parts of this project were described elsewhere [31, 32]. The entire sample was comprised of 87 subjects: 48 ART patients ( 25 mothers and 23 fathers) and 39 non-ART mothers. ART subjects were recruited between April 2005 and December 2006 from patients of Italian nationality. Only 35 couples (and one woman) of the 122 eligible ART couples (61 women and their partners) attending our Center agreed to participate in the longitudinal study. However, only 57 were finally included in the study because we excluded couples residing far from the hospital. The drop-out rate at each follow-up visit was as follows: $2.8 \%$ (men and women) at the first assessment because of preterm birth; $2.8 \%$ were lost for follow-up by the second assessment, and $1.4 \%$ of women and $5.6 \%$ of men could not be reached for the last follow-up evaluation.

For the non-ART sample, 224 women meeting the same inclusion criteria were recruited at the obstetric ward of the same hospital, but only 39 women were ultimately included in the study, after matching for gestational age, mode of delivery, plurality, and parity. Men were not included in this study because very few were willing and able to participate in the longitudinal study. During the postnatal assessment, one woman of the nonART sample could not be reached for the postnatal interview, and the sample for the second assessment consists of 38 women only. The study design was approved by the Institutional Review Boards of the University of Bologna and the Hospital of Santa Maria Nuova, Reggio Emilia, Italy.

\section{Procedure}

The psychologists involved in this project contacted the subjects at 20-24 weeks' gestation to explain the objective of the longitudinal project, and to receive an informed consent. At 30-32 weeks of gestation, the psychologists (one interviewer at a time, no co-rater) visited the couples at home and introduced two questionnaires, one on anxiety [32] and one on depression symptomatology [31]. During the same visit, the psychologists conducted interviews on maternal representations (Intervista per le rappresentazioni materne in gravidanza, IRMAG; 2) and on paternal representations (Intervista per le rappresentazioni paterne in gravidanza, Ra.Pa.G; 11). At three months after birth, the psychologists visited again the couples at home, completed the depression and anxiety questionnaires and interviewed the subjects on maternal and paternal representations after birth (Intervista sulle rappresentazioni materne e paterne dopo la nascita, respectively the Rap.Ma.N. and Rap.Pa.N; 11). As per definition of the study, the interviewers were not blinded to the mode of conception.

\section{Instruments}

The interviews on parental representations during pregnancy (maternal: IRMAG; paternal representations: Rap.Pa.G) and after birth (maternal: Rap.Ma.N.; paternal: Rap.Pa.N) are semi-structured interviews (41 open questions), that stimulate the subject to relate his/her experience to the period of the pregnancy and to the transition to parenthood. These interviews investigate the way in which the subjects organize, within a narrative structure, their experience regarding parenthood, in representation of oneself as a parent and representation of the baby.

The first representation focuses on how the subject (a) relates the desire for parenthood, the emotions felt, and the changes in life brought about by pregnancy and birth; (b) imagines his/her and his/her partner's parental function and capability, (c) his/her ability to organize the rhythms of the new life situation, and (d) also focusing on historic perspective, by comparing what was experienced during childhood and the parental style of his/her own parent. The second area investigates the perceptive aspects, the emotions, and the maternal and paternal fantasies associated to the so-called "imaginary baby", the image that every parent builds in his/her mind during pregnancy about the soon-to-be-born baby, and all that is associated postpartum to the characteristics of the real baby.

Seven dimensions are used to study the narrative model [2]:

- Richness of perceptions: evaluates the way in which episodes, sensations, emotions, and behavior of oneself and of the baby are described.

- Openness to change: evaluates the subject's flexibility to adapt to the psychological and/or physical transformations happening to him/her and to the baby.

- Intensity of investment: measures the extent of the subject's psychological involvement in dealing with experiences relat- 
ed to the pregnancy, the baby, and to the relationship with him/her.

- Coherence: the ability of giving a comprehensible description of himself/herself as a parent, of the baby and of the relationship with him/her, through a well-organized and logical narrative flux of ideas and emotions.

- Differentiation: evaluates the degree of consciousness of one's own (or the baby's) stable mental and physical characteristics, of one's own (or the baby's) specific needs and desires, differentiated from those of the partner and of the parental figures.

- Social dependency: evaluates the degree of influence and dependency of the representation of oneself as a parent and of the baby from the messages coming from the partner, family of origin, friends, and social context.

- Dominance of fantasies: measures the emergence of fantasies, the collection of desires, expectation and fears that connote the representations of oneself as a parent and of the baby.

These seven dimensions are codified on a five-point rating scale (from 1 to 5). The final score identifies three different styles of parental representation and narratives [2]:

- Well integrated/balanced: representations of parenthood are coherent, open to changes and rich in episodes, permeated by an intense emotional involvement. The pregnancy and the baby represent a very important stage of personal development.

- Restricted/disengaged: a strong emotional control and a sense of impersonality prevail in the narration; the subject expresses mechanisms of rationalization and rigidity regarding the whole experience of becoming a parent and his/her involvement with the baby.

- Not integrated/ambivalent: contrasting behavior (an excessive involvement and a struggle to keep distance) are present regarding parenthood and/or the baby. The narration is often confused, with many episodes but with low coherence.

\section{Data analysis}

We compared between ART and non-ART women and between ART women and ART men. We used the $\chi^{2}$ and Fisher's exact tests to compare the frequency of subjects for the levels of socio-demographic variables and for the three main categories of parental representations at each assessment. The scores of each dimension of the maternal/paternal representations were compared using Student's $t$-test for independent samples. Mixed ANOVA was used for the longitudinal comparison and to evaluate the interaction between $A R T$ condition (yes/no;

Table 1 Comparison between ART and non-ART women and between ART women and men for the main socio-demographic characteristics. Data presented as n (\%).

\begin{tabular}{|c|c|c|c|c|c|}
\hline & \multicolumn{2}{|l|}{ Women } & \multirow[t]{2}{*}{ P-value } & \multirow{2}{*}{$\frac{\text { Men }}{\text { ART }}$} & \multirow[t]{2}{*}{ P-value } \\
\hline & ART & Non-ART & & & \\
\hline $\mathrm{n}$ & 25 & 39 & & 23 & \\
\hline Mean age (years) & $35.9 \pm 3.2$ & $32.1 \pm 3.6$ & 0.0005 & $39.5 \pm 4.7$ & 0.004 \\
\hline \multicolumn{6}{|l|}{ Place of birth (Italy) } \\
\hline North & $16(64)$ & $27(73)$ & 0.36 & $14(60.9)$ & 0.64 \\
\hline Central & $2(8)$ & - & & $1(4.3)$ & \\
\hline South & $6(24)$ & $8(21.6)$ & & $8(34.8)$ & \\
\hline Abroad & $1(4)$ & $2(5.4)$ & & - & \\
\hline \multicolumn{6}{|l|}{ Residence } \\
\hline Northern Italy & $24(96)$ & $39(100)$ & 0.39 & $22(95.7)$ & 1.00 \\
\hline Central Italy & $1(4)$ & - & & $1(4.3)$ & \\
\hline Urban residence & $13(52)$ & 27 (69.2) & 0.19 & $12(52.2)$ & 1.00 \\
\hline \multicolumn{6}{|l|}{ Education } \\
\hline Primary school & $1(4)$ & - & 0.14 & - & 0.52 \\
\hline Secondary school & $3(12)$ & $8(20.5)$ & & $5(21.7)$ & \\
\hline High school & $9(36)$ & $21(53.8)$ & & $10(43.5)$ & \\
\hline University & $12(48)$ & $10(25.6)$ & & $8(34.8)$ & \\
\hline \multicolumn{6}{|l|}{ Profession } \\
\hline Housewife & - & $2(5.1)$ & 0.60 & $1(4.3)$ & 0.27 \\
\hline Factory worker & $5(20)$ & $5(12.8)$ & & $4(17.4)$ & \\
\hline Employee & $17(68)$ & $28(71.8)$ & & $11(47.8)$ & \\
\hline Professional employee & $3(12)$ & $4(10.3)$ & & $7(30.4)$ & \\
\hline \multicolumn{6}{|l|}{ Social class } \\
\hline High & $4(16)$ & $7(19.4)$ & 0.91 & $6(30)$ & 0.53 \\
\hline Middle & $16(64)$ & $23(63.9)$ & & $11(55)$ & \\
\hline Low & $5(20)$ & $6(16.7)$ & & $3(15)$ & \\
\hline \multicolumn{6}{|l|}{ Marital status } \\
\hline Married & $22(88)$ & $31(79.5)$ & 0.52 & $20(87)$ & 0.99 \\
\hline Co-habiting & $2(8)$ & $7(17.9)$ & & $2(8.7)$ & \\
\hline Separated/divorced & $1(4)$ & $1(2.6)$ & & $1(4.3)$ & \\
\hline
\end{tabular}


between-subjects factor) and time of assessment (pre/postnatal; within-subjects factor).

\section{Results}

\section{Sample characteristics}

ART and non-ART women had similar main socio-demographic characteristics (Table 1) namely, the majority were born in Northern Italy, had a higher level of education, were married, were employed, belonged to middle social class and were Catholic. As for the main obstetrical variables, these two samples had similar parity, plurality, mode of delivery, and frequency of attendance in antenatal classes (Table 1). Differences were found in maternal age (ART women were older than nonART women, 35.9 vs. 32.1 years, $\mathrm{P}<0.0005)$ and in period of cohabitation (ART women more frequently lived together with their partner for more than 8 years, 48 vs. $10.3 \%, P=0.001)$. The comparison between ART women and ART men showed that women were younger (35.9 vs. 39.5 years, $P=0.004)$, but had otherwise similar socio-demographic characteristics (Table 1).

\section{Parental representations}

ART vs. non-ART women Comparisons were made between the two groups for the mean scores of each of the 14 dimensions of the IRMAG interview (7 concerning the representation of oneself-as-mother and 7 concerning the representation of the fetus/baby). During the $3^{\text {rd }}$ trimester of pregnancy, ART women obtained significantly higher scores of representation of oneself-asmother compared to non-ART women in intensity of investment $(3.8 \pm 0.9$ vs. $3.4 \pm 0.6, P=0.05)$, differentiation ( $3.2 \pm 0.6$ vs. $2.9 \pm 0.7, P=0.03$ ) and dominance of fantasies ( $3.1 \pm 0.8$ vs. $2.7 \pm 0.6, P=0.03$ ), but not for the dimensions related to the representation of the fetus/ baby. At three months after birth, no significant differences were detected between the two groups regarding the representations of themselves as mothers, except for differentiation $(3.0 \pm 0.7$ vs. $2.6 \pm 0.7, P=0.05)$, as well the representation of the fetus/baby.

When the change from before to after birth was analyzed, a borderline significant interaction between $A R T$ condition and time of assessment (pre/postnatal) was found $(P=0.05)$ related to the intensity of investment (representation of oneself-as-mother), suggesting that ART women tend to decrease the scores with time, when compared to non-ART women (before delivery: 3.8 vs. 3.4; after delivery: 3.1 vs. 3.2). When the three main categories of representation were considered, a significant difference was found between ART and non-ART women during the third trimester of pregnancy $(P=0.01)$ : ambivalent representations were present more frequently in the former whereas well integrated representations were present less frequently (Table 2). At three months postpartum, again, ART women showed higher frequency of ambivalent representations and a lower frequency of well integrated representations when compared to non-ART women ( $P=0.03$, Table 2).

ART women vs. ART men During the $3^{\text {rd }}$ trimester of pregnancy, ART women showed significantly higher mean scores than ART men in the following dimensions related to the representation of oneself-as-parent: richness of perceptions $(3.5 \pm 0.7$ vs. $3.0 \pm 1.0, P=0.03)$, social dependency $(3.1 \pm 0.7$ vs. $2.5 \pm 0.8, P=0.01)$ and dominance of fantasies ( $3.1 \pm 0.8$ vs. $2.6 \pm 1.0, P=0.05$, Table 3). Regarding the representation of the fetus/baby, social dependency was significantly higher in ART women compared to ART men ( $P=0.005$, Table 3$)$. At three months after birth, no significant differences were noted between the two groups (Table 3).

When the change from before to after birth was analyzed, a significant interaction between sex (women/men) and time of assessment (pre/postnatal) was found $(P=0.006)$, related to richness of perceptions (representation of oneself-as-parent): whereas women had significantly higher scores than men before delivery (3.5 vs. 3.0), these scores tend to decrease after birth (3.0 vs. 3.1). Another significant interaction was related to intensity of investment (representation of oneself-as-parent;

Table 2 Frequencies of maternal representations in ART/non-ART condition and of paternal representation in ART.

\begin{tabular}{|c|c|c|c|c|c|}
\hline & $\begin{array}{l}\text { ART women } \\
(n=25)(\%)\end{array}$ & $\begin{array}{l}\text { Non-ART women } \\
(n=38)(\%)\end{array}$ & P-value & $\begin{array}{l}\text { ART men } \\
(n=23)(\%)\end{array}$ & P-value \\
\hline \multicolumn{6}{|c|}{$3^{\text {rd }}$ trimester of pregnancy } \\
\hline Well integrated & 48 & 76.9 & 0.01 & 43.5 & 0.005 \\
\hline Ambivalent & 36 & 7.7 & & 4.3 & \\
\hline Disinvested & 16 & 15.4 & & 52.2 & \\
\hline 3 months after birth & & & 0.03 & & \\
\hline Well integrated & 45.8 & 71.8 & & 54.5 & 0.02 \\
\hline Ambivalent & 41.7 & 12.8 & & 9.1 & \\
\hline Disinvested & 12.5 & 15.4 & & 36.4 & \\
\hline
\end{tabular}


Table 3 Mean scores and SD of the 14 dimensions derived from IRMAG and IRMAN interview in ART women and men.

\begin{tabular}{|c|c|c|c|c|c|c|}
\hline \multirow[t]{2}{*}{$3^{\text {rd }}$ trimester of pregnancy } & \multicolumn{3}{|c|}{ IRMAG interview } & \multicolumn{3}{|c|}{ IRMAN interview } \\
\hline & $\begin{array}{l}\text { ART women } \\
(n=25)\end{array}$ & $\begin{array}{l}\text { ART men } \\
(n=23)\end{array}$ & P-value & $\begin{array}{l}\text { ART women } \\
(n=25)\end{array}$ & $\begin{array}{l}\text { ART men } \\
(n=23)\end{array}$ & P-value \\
\hline \multicolumn{7}{|c|}{ Representation of Self-as-mother/father } \\
\hline Richness of perceptions & $3.52(0.71)$ & $2.96(1.02)$ & 0.03 & $2.96(0.62)$ & $3.14(0.99)$ & 0.47 \\
\hline Openness to change & $3.16(0.75)$ & $2.96(0.82)$ & 0.37 & $2.96(0.69)$ & $3.18(0.73)$ & 0.29 \\
\hline Intensity of investment & $3.76(0.88)$ & $3.39(0.78)$ & 0.13 & $3.12(0.85)$ & $3.45(0.91)$ & 0.21 \\
\hline Coherence & $3.16(0.75)$ & $3.13(0.55)$ & 0.88 & $3.08(0.72)$ & $3.23(0.61)$ & 0.47 \\
\hline Differentiation & $3.24(0.60)$ & $3.22(0.60)$ & 0.90 & $3.0(0.66)$ & $3.09(0.61)$ & 0.63 \\
\hline Social dependency & $3.08(0.70)$ & $2.52(0.79)$ & 0.01 & $2.67(0.70)$ & $2.50(0.91)$ & 0.47 \\
\hline Dominance of fantasies & 3.08. $(0.76)$ & $2.56(0.99)$ & 0.05 & $2.67(0.71)$ & $2.82(0.96)$ & 0.54 \\
\hline \multicolumn{7}{|c|}{ Representation of the fetus/baby } \\
\hline Richness of perceptions & $3(0.82)$ & $2.61(0.84)$ & 0.11 & $3.00(0.93)$ & $2.86(0.83)$ & 0.60 \\
\hline Openness to change & $2.92(0.49)$ & $2.83(0.83)$ & 0.63 & $2.75(0.67)$ & $3.0(0.69)$ & 0.22 \\
\hline Intensity of investment & $3.44(1.19)$ & $3.0(0.95)$ & 0.17 & $3.12(0.85)$ & $3.09(1.06)$ & 0.90 \\
\hline Coherence & $3.16(0.62)$ & $2.96(0.56)$ & 0.24 & $3.04(0.62)$ & $3.0(0.76)$ & 0.84 \\
\hline Differentiation & $2.88(0.78)$ & $2.65(0.65)$ & 0.28 & $2.83(0.64)$ & $2.91(0.68)$ & 0.70 \\
\hline Social dependency & $2.96(0.67)$ & $2.39(0.66)$ & 0.005 & $2.80(0.51)$ & $2.59(0.80)$ & 0.31 \\
\hline Dominance of fantasies & $2.84(0.69)$ & $2.39(0.89)$ & 0.056 & $2.83(0.56)$ & $2.64(0.85)$ & 0.35 \\
\hline
\end{tabular}

$P=0.04)$ : women scored lower over time (3.8 vs. 3.4), whereas men tend to maintain similar levels (3.1 vs. 3.4).

When the three main categories of representation were considered, a significant difference was found between ART women and ART men during the third trimester of pregnancy $(P=0.005)$ : ART women showed a higher frequency of ambivalent representations when compared to ART men, whereas the latter group had a higher percentage of disengaged representations (Table 2). At three months after birth, a significantly higher number of ambivalent representations was detected in ART women compared to ART men ( $P=0.02$, Table 2).

\section{Discussion}

This is one of the few studies on parental representations during and following ART pregnancies. Several studies on parental representations were recently published [22, 26, 34-36], but were not specifically related to ART. Significantly higher scores were found in our study among ART and non-ART pregnancies at the third trimester of pregnancy related to dominance of fantasies and differentiation. These should be considered a normal psychological expression in ART women because of their greater feeling of involvement in a pregnancy that has long been desired. ART women consider their pregnancies as more "precious" [23, 34] and focus more intensely on all potential risks, in the sense that "the coming baby could mend everything, fill everything" [6]. This observation might explain why this same ART sample was characterized by a higher level of anxiety [32] related to worries about a happy ending to the pregnancy. A different explanation might relate to the dimension of differentia- tion, which represents the degree of awareness the woman has of her specific needs, wishes, and expectations, as being differentiated from those of her partner and her own parents, especially of her mother [2]. The higher scores for this dimension in ART women, both before and after delivery, could signal a more intense need of differentiating their personal experience of motherhood from their own mother's experience. In a psychodynamic approach, generativity is transmitted from mother to daughter [6, 47], but this process is strongly thwarted by sterility which reflects, in comparison with her own mother, an image of incapability. Thus, ART could be experienced by the woman as something which is only hers, characterized by a higher degree of differentiation from her own mother that lacks intergenerational psychological transmission. We acknowledge the significant difference in maternal age between the study and control women, suggesting that some of the differences found in this study might be age-related. However, advanced age is an inherent part of ART and it would be quite impossible to control for the age-factor in such analysis.

At three months after birth, intensity of investment showed a significant decrease in ART women. This interesting observation may underline that, in the representation of herself-as-mother, the most important factor is being pregnant. Pines suggested the important distinction between desire for pregnancy and desire for maternity [37, 38], which do not always coincide. Many women primarily wish to conceive and the need of a child can often be confused with the desire for a child. This confusion could be greater in ART treatments where the desire for pregnancy becomes an imperative need to verify the functioning of one's own body. Of particular interest is the observation that no differences exist between 
ART and non-ART women in the representation of the fetus/baby, suggesting a similar process of imagining the future child irrespective of the mode of conception, but, at the same time, the psychological changes related to the transition to parenthood are more influenced by ART.

The focus on the pregnancy rather than on the future child might be related to the inability of building an integrated representation of the motherhood process. In fact, when the three main categories of representation which might predict the postpartum parental style were considered (Table 2), a higher frequency of ambivalent representations and a lower frequency of well integrated ones were observed in ART compared to non-ART women. This might be a sign of a greater psychological vulnerability in ART pregnancy, where, despite the tendency to be more intensely involved, there is a higher difficulty in obtaining an integrated view of positive and negative as well as real and imaginary elements [1, 13].

When ART women are compared to ART men, the former showed an expected higher psychological involvement in pregnancy. As in spontaneous pregnancies, women feel more involved in the process because pregnancy is not only embodied in their mind but also in their body. For this reason, ART women scored higher than ART men for richness of perception and for dominance of fantasies during pregnancy (but not after). Moreover, before delivery, women differed from men in relation to social dependency, which is the need to give a somewhat conformistic image of themselves-as-mothers and of their babies [1]. It might be hypothesized that a greater need exists for the woman to show, at a social level, her ability to generate. In this sense, the representation of an ART pregnancy can be associated with feelings of shame, guilt, and isolation. When compared to ART men, ART women showed a higher frequency of ambivalent representations both before and after delivery, whereas ART men were characterized by a higher frequency of disengaged representations. These results are also expected in spontaneous pregnancies because of the lower level of involvement of men. However, an important element is that ART representations, maternal and paternal, both before and after delivery, were integrated only in $40-50 \%$ of cases; and ART men showed a limited paternal investment on the relationship with the child. Thus, even the most motivated of ART fathers could feel "pushed to the outskirts of the child project by the biomedical technology" [6].

Previous studies $[9,10,14,18,24]$ showed that children conceived by ART had a relatively normal development, whilst the experience of parenthood seemed to be very delicate. The present study supports the importance of paying attention to the complexity of the psychological process of becoming an ART parent, because the parent needs to cope with the difficult relationship with a real baby, to keep ART as a secret, to continuously grieve the presence of infertility, and to cope with the presence of a narcissistic wound which will never completely heal [15, 33]. Thus, children conceived by ART are not "special children" but their parents think of themselves as "special parents" [15].

Within the limitations of a relatively small sample, potential (but unlikely) bias introduced by non-blinded interview, and the potential but inevitable confounding of maternal age, our longitudinal study could nevertheless highlight the clinical importance of studying parental representations. These representations play an important role in predicting parenting styles and might help understanding how parents will be able to co-construct the caring relationship with the child [12]. Without accurate psychosocial assessment and/or intervention, potentially traumatic situations like ART pregnancies may incur enactment of negative mental representations during the postpartum period. This risk calls for further research on the relationship between mental representation and psychological morbidity in ART pregnancies.

\section{References}

[1] Ammaniti M, Baumgartner E, Candelori C, Perucchini P, Pola M, Tambelli R, et al. Representations and narratives during pregnancy. Infant Ment Health J. 1992;2:167-82.

[2] Ammaniti M, Candelori C, Pola M, Tambelli R. Maternità e gravidanza: Studio delle rappresentazioni materne. Milano: Raffaello Cortina; 1995.

[3] Andreotti S, Bucci AR, Marozza MI. Gravidanza FIVET: Rappresentazioni materne ed aspetti psicologici. In: Casadei D, Righetti PL, editors. L'intervento psicologico in ginecologia. Roma: Edizioni Magi; 2007. pp. 227-37.

[4] Ansermet F. Clinique de l'origine: L'enfant entre la médecine et la psychanalyse. Lausanne: Payot; 1999.

[5] Bowlby J. A secure base: clinical applications of attachment theory. London: Routledge \& Kegan Paul; 1988.

[6] Bydlowski M. La dette de la vie: Itinéraire psychanalytique de la maternité. Paris: PUF; 1997.

[7] Candelori C, Perucchini P, Pola M, Tambelli R. Stabilità e cambiamento delle rappresentazioni materne in gravidanza e nel periodo postnatale. In: Ammaniti M, editor. La gravidanza tra fantasia e realtà. Roma: II Pensiero Scientifico; 1992. pp. 121-38.

[8] Catalano R, Ingrassia RR, Bazzano M. Concepire un desiderio. Viaggio nell'immaginario di coppie in gravidanza con riproduzione assistita. Atti del III Congresso nazionale di Psicologia clinica dell'AIP, Palermo, 28-30 settembre. Roma: Edizioni Carlo Amore; 2001. pp. 319-320.

[9] Colpin H, De Munter A, Vandemeulebroecke L. Parenthood motives in IVF-mothers. J Psychosom Obstet Gynaecol. 1998;19:19-27.

[10] Cook R, Bradley S, Golombok S. A preliminary study of parental stress and child behaviour in families with twins conceived by in-vitro fertilization. Hum Reprod. 1998;13: 3244-6.

[11] Di Vita AM, Giannone F, editors. La famiglia che nasce: Rappresentazioni e affetti dei genitori all' arrivo del primo figlio. Milano: Franco Angeli; 2002. 
[12] Emde RN, Sameroff AJ, Anders TF, editors. Relationships disturbances in early childhood: a developmental approach. New York: Basic Books; 1989.

[13] Epelboin S. Uguale ma diversa: la gravidanza ottenuta ricorrendo alle tecniche di procreazione medicalmente assistita. In: Mimoun S, Maggioni C, editors. Trattato di ginecologia ostetricia psicosomatica. Milano: Franco Angeli; 2003. pp. 290-302.

[14] Fagandini P, Bevolo P, Landini A, Vaccai P. Bambini e genitori speciali? Primi risultati di una ricerca condotta in Emilia-Romagna. In: La Sala GB, editor. Bambini e genitori speciali?: Dal bambino desiderato al bambino reale. Roma: Carrocci; 1999. pp. 241-54.

[15] Fagandini P, Monti F, Agostini F, Fava R, La Sala GB. La complessità della genitorialità: Esperienza materna $\mathrm{e}$ paterna tra sterilità e procreazione. In: La Sala GB, lori V, Monti F, Fagandini P, editors. La "normale" complessità del venire al mondo: Incontro tra scienze mediche e scienze umane. Milano: Guerini Studio; 2006. pp. 173204.

[16] Fonagy P, Steele H, Steele M. Maternal representations of attachment during pregnancy predict the organization of infant-mother attachment at one year of age. Child Dev. 1991;62:891-905.

[17] Fonagy P, Gergely G, Jurist EL, Target M. Affect regulation, mentalization and the development of the self. New York: Other Press; 2002.

[18] Gibson FL, Ungerer JA, Leslie GI, Saunders DM, Tennant CC. Development, behavior and temperament: a prospective study of infants conceived through in-vitro fertilization. Hum Reprod. 1998;13:1727:32

[19] Hjelmstedt A, Widström AM, Wramsby H, Matthiensen AS, Collins A. Personality factors and emotional responses to pregnancy among IVF couples in early pregnancy: a comparative study. Acta Obstet Gynecol Scand. 2003; 82:152-61.

[20] Hsu YL, Kuo BJ. Evaluations of emotional reactions and coping behaviours as well as correlated factors for infertile couples receiving assisted reproductive technologies. J Nurs Res. 2002;10:291-302.

[21] Huth-Bocks AC, Levendosky AA, Bogat GA, van Eye A The impact of maternal characteristics and contextua variables on infant-mother attachment. Child Dev. 2004; 75:480-96.

[22] Ilicali ET, Fisek GO. Maternal representations during pregnancy and early motherhood. Infant Ment Health $\mathrm{J}$. 2004;25:16-27.

[23] Klaus MH, Kennel JH. Maternal infant bonding. Saint Louis: The C.V. Mosby Company; 1976.

[24] La Sala GB, Landini A, Fagandini P, Torricelli L, Leni M. Developmental outcomes at one and two years of children conceived by intracytoplasmatic sperm injection. Int J Fertil. 2003;49:113-9.

[25] Leckman JF, Feldman R, Swain JE, Eicher V, Thompson $\mathrm{N}$, Mayes LC. Primary parental preoccupation: Circuits, genes, and the crucial role of the environment. J Neural Transm. 2004;111:753-71.

[26] Leckman JF, Mayes LC. Nurturing resilient children. J Child Psychol Psychiatry. 2007;48:221-3.

[27] Lok IH, Lee DT, Cheung LP, Chung WS, Lo WK, Haines CJ. Psychiatric morbidity amongst infertile Chinese women undergoing treatment with assisted reproductive technology and the impact of treatment failure. Gynecol Obstet Invest. 2002;53:195-9.
[28] Lyons-Ruth K, Block D. The disturbed care-giving system: Relations among childhood trauma, maternal caregiving and infant affect, and attachment. Infant Ment Health J. 1996;17:257-75.

[29] Mazzoni S. Tossicomania e gravidanza. In: Ammaniti M, editor. La gravidanza tra fantasia e realtà. Roma: II Pensiero Scientifico; 1992. pp. 217-35.

[30] McMahon CA, Ungerer JA, Tennant C, Saunders D. Psychosocial adjustment and the quality of the mother-child relationship at four months postpartum after conception by in vitro fertilization. Fertil Steril. 1997;68:492-500.

[31] Monti F, Agostini F, Fagandini P, La Sala GB, Blickstein I. Depressive symptoms during late pregnancy and early parenthood following assisted reproductive technology. Fertil Steril. 2008; Mar 1. [Epub ahead of print].

[32] Monti F, Agostini F, Fagandini P, Paterlini M, La Sala GB, Blickstein I. Anxiety symptoms during late pregnancy and early parenthood following assisted reproductive technology. J Perinat Med. 2008; in press.

[33] Nerson-Sachs C. Soggetto nella procreazione medicalmente assistita: riflessioni psicologiche e psicopatologiche. In: Mimoun S, Maggioni C, editors. Trattato di ginecologia ostetricia psicosomatica. Milano: Franco Angeli; 2003. pp. 303-25.

[34] Pajulo M, Savonlahti E, Sourander A, Helenius H, Piha J. Prenatal maternal representations: Mothers at psychosocial risk. Infant Ment Health J. 2001;22:529-44.

[35] Pajulo M, Savonlahti E, Sourander A, Helenius H, Piha J. Maternal representations, depression and interactive behaviour in the postnatal period. A brief report. J Reprod Infant Psychol. 2004;22:91-8.

[36] Pajulo M, Helenius H, Mayes L. Prenatal views of baby and parenthood: Association with sociodemographic and pregnancy factors. Infant Ment Health J. 2006;22:229-50.

[37] Pines D. Pregnancy and motherhood: interaction between fantasy and reality. Br J Med Psychol. 1972;45:333-43.

[38] Pines D. Adolescent pregnancy and motherhood: a psychoanalytic perspective. Psychoanalytic Inquire. 1988;8: 234-51.

[39] Raphael-Leff J. Psychological processes of childbearing. London: Chapman and Hall; 1991.

[40] Sayre JM, Pianta RC, Marvin RS, Saft EW. Mothers' representations of relationships with their children: Relations with mother characteristics and feeding sensitivity. $J$ Pediatr Psychol. 2001;26:375-84.

[41] Schuler ME, Nair P, Black MM, Kettinger L. Mother-infant interaction: Effects of a home intervention and ongoing maternal drug use. J Clin Child Psychol. 2000;29:424-31.

[42] Siddiqui A, Hägglöf B, Eisemann M. Own memories of upbringing as a determinant of prenatal attachment in expectant women. J Reprod Infant Psychol. 2000;18: 67-74.

[43] Slade A, Belsky J, Aber JL, Phelps JL. Mothers' representations of their relationship with their toddlers: Links to adult attachment and observed mothering. Dev Psychol. 1999;35:611-19.

[44] Slade A. Keeping the baby in mind: A critical factor in perinatal mental health. Zero to Three. 2002;6:10-6.

[45] Stern DN. The motherhood constellation: A unified view of parent-infant-psychotherapy. New York: Basic Books; 1995.

[46] Stern DN, Bruschweiler-Stern N. The birth of a mother. How the motherhood experience changes you forever. New York: Basic Books; 1998. 
[47] Winnicott DW. Through pediatrics to psychoanalysis. New York: Basic Books; 1958.

[48] Zeanah CH, Keener MA, Stewart L, Anders TF. Prenatal perception of infant personality. J Am Acad Child Psychiatry. 1985;24:204-10.

[49] Zeanah CH, Keener MA, Anders TF. Adolescent mothers' prenatal fantasies and working models of their infants. Psychiatry. 1986;49:193-203.

[50] Zeanah CH, Barton ML. Introduction: Internal representations and parent-infant relationships. Infant Ment Health J. 1989;3:135-41.
[51] Zeanah CH, Benoit D. Clinical applications of a parent perception interview in infant mental health. Child Adolesc Psychiatr Clin N Am. 1995;4:539-54.

The authors stated that there are no conflicts of interest regarding the publication of this article.

Received October 3, 2008. Revised November 25, 2008. Accepted November 27, 2008. Previously published online March 17, 2009. 